\title{
Influence of Variously Modified Surface of Aluminium Alloy on the Effect of Pulsating Water Jet
}

\author{
Jiri Klich* - Dagmar Klichova - Vladimir Foldyna - Petr Hlavacek - Josef Foldyna \\ Institute of Geonics of the CAS, Czech Republic
}

Erosion effects of a pulsating water jet impinging the surface of aluminium alloy samples pre-treated by various techniques (rough and fine milling, planing and rolling) were studied. The influence of the initial surface topography on the final topography of the sample exposed to the pulsating water jet was investigated. Based on roughness parameter Ra erosion of surface layers was analysed and discussed in relation to the traversing speed of the jet. It was found that initial surface pre-treatment have a significant impact on the final topography of the surface affected subsequently by pulsating water jet. Surfaces, whose properties are significantly affected by the action of some machining processes (i.e. milling) show much greater resistance to pulsating water jet than unpaved surfaces (i.e. rolling) and surfaces have smaller roughness. While milled (rough or fine) or planed surface roughness has approximately the same increase of Ra parameter, only rolled surfaces are up to 150 times rougher after pulsating water jet treatment. This is due to the small hardening of the surface layers and reduced durability against pulsating water jet in comparison with others investigated techniques. The highest roughness was achieved on all pre-treated surfaces at the lowest speeds, because the pulsating water jet affects the surface for a longer time.

Keywords: pulsating water jet, surface topography, material erosion

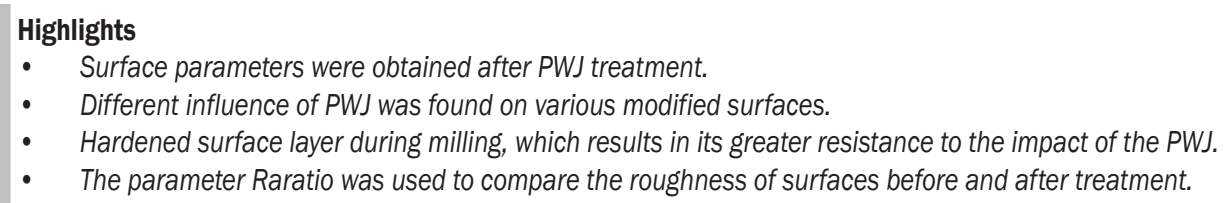

- $\quad$ Surface parameters were obtained after PWJ treatment.

- $\quad$ Different influence of PWJ was found on various modified surfaces.

- Hardened surface layer during milling, which results in its greater resistance to the impact of the PWJ.

- The parameter Raratio was used to compare the roughness of surfaces before and after treatment.

\section{INTRODUCTION}

Over hundred years, researchers have been interested in the interaction of a liquid with a solid. One of the first researchers dealing with this subject was Cook [1] who wrote his article on the surface erosion in 1928. He clearly recognized the importance of the water hammer pressure.

Pulsating water jet (PWJ) has been successfully used for several industrial applications. Pulsating water jet is an extension of the conventional (continuous) jet, consisting of an array of high-speed water pulses. When a pulsating water jet impinges a target, the momentum flux through the nozzle is not transmitted to the target material as a steady force, but as a discontinuous sequence of impacts, creating high momentary stresses in the impingement zone. As a result, the peak pressure acting on the surface is not the stagnation pressure, but the significantly higher water hammer pressure [2] and [3].

There are several ways how to create the pulsating water jet as shown, for instance, in [4]. It can be done using mechanical interrupters, self-resonating systems, jets modulation by the piezoelectric magnetostrictive effects, jet disruption by electric discharge, laser based pulsating of water jets, etc. In our case, the system for the generation of acoustic pulsations developed at the Institute of Geonics of the ASCR, v. v. i. was used [5] to [7].

The high-speed pulsating water jets are generated by sufficiently high pressure pulsations in pressure water in the upstream direction to the nozzle exit. In the nozzle, the pressure pulsations change into speed pulsations and the jet emerges from the nozzle exit as a continuous jet with variable axial speed. Owing to the variable speed, the jet is formed into pulses at a certain stand-off distance towards the nozzle exit (so called forced break-up length of the jet) and it starts acting as a pulsating jet. Exploitation of effects related to the water pulses impingement on solids in the field of the high-speed water jet technology should result in considerable improvement of its performance, better adaptation to progressively more demanding environmental requirements and, consequently, more cost-saving use of the technology from the economical point of view [8].

Unlike classical continuous water jet, pulsating water jet is able to create different final texture in surface treatment and it is several times more effective [2].

The objective of the paper is to determine erosion effects of the pulsating water jet impinging the surface of aluminium alloy samples treated by various techniques (rough and fine milling, planing 
and rolling) and to discuss the influence of the initial surface topography on the final topography of the sample exposed to the pulsating water jet.

\section{METHODS}

Kerfs were formed successively with pulsating water jet on test samples. These aluminium alloy samples were pre-treated with various technological processes. Subsequently, surface roughness was obtained. We suppose that surface pre-treatment by various forming and machining techniques has significant influence on disintegration ability of subsequently applied pulsating water jet due to surface strengthening by particular technique ([9] and [10]).

The facility used for the experiment consisted basically of a high-pressure water supply system, pulsating water jet generator, robotic manipulator ABB IRB 6640-180/2.55 Master for traversing the jet over test samples and optical surface profilometer MicroProf FRT for the evaluation of surface characteristics of the samples [11].

The high-pressure water was supplied to the generator of pulsating water jet by a plunger pump Hammelmann HDP 253 able to deliver up to $651 \cdot \mathrm{min}^{-1}$ of water at the operating pressure up to $160 \mathrm{MPa}$. The generator was equipped with a commercially available fan nozzle with the equivalent orifice diameter of 2.0 $\mathrm{mm}$ and the spraying angle of $10^{\circ}$.

The generator of pulsating water jet was designed for the maximum operating pressure of $150 \mathrm{MPa}$. It consisted of a piezoelectric transducer vibrating at the operating frequency of about $20 \mathrm{kHz}$ and it was driven by an ultrasonic generator Ecoson with the maximum output power of $800 \mathrm{~W}$.

Test samples were manufactured from the aluminium alloy from Alfun Company known as EN AW 5083 H111 (Table 1). This alloy was chosen, because it is frequently used in construction. Industry often requires surface treatment of this material.

Table 1. Aluminium alloy EN AW $5083 \mathrm{H} 111$

\begin{tabular}{cccc}
\multicolumn{2}{c}{ Chemical composition [wt. \%] } & & \\
\cline { 1 - 3 } $\mathrm{Al}$ & $\mathrm{Mg}$ & $\mathrm{Mn}$ & \\
\cline { 1 - 3 } 94.8 & 4.5 & 0.7 & \\
\cline { 1 - 3 } \multicolumn{2}{c}{ Mechanical properties } & & Hardness \\
\cline { 1 - 3 } Yield strength & Tensile strength & Elongation & Brinell [HB] \\
$\sigma_{0.2}[\mathrm{MPa}]$ & $\sigma_{\mathrm{Pt}}[\mathrm{MPa}]$ & $A_{50}[\mathrm{~mm}]$ & 75 \\
\hline 125 & 275 & 12 & \\
\hline
\end{tabular}

Firstly, the abrasive water jet technology was used to cut the samples from $10 \mathrm{~mm}$ thick sheet in order to eliminate thermal effects on the properties of samples [12] to [14]. Dimensions of the test samples were $10 \mathrm{~mm} \times 60 \mathrm{~mm} \times 100 \mathrm{~mm}$ (Fig. 1). Secondly, the samples surface was treated by rough milling, fine milling and planing. One sample remained untreated; its surface was only affected by rolling during the aluminium sheet manufacturing. Parameters of the used technological operations are presented in Table 2. Then, surfaces were scanned by an optical profilometer to determine the initial surface roughness of the prepared samples (before their exposition to the pulsating water jet) [15] and [16].

To compare the roughness of surfaces before and after treatment of the PWJ, the parameter $R a_{\text {ratio }}$ (Eq. (1)) was used, where $R a$ represents the roughness of surface after the PWJ treatment and $R a_{i n i}$ represents the roughness of initial surface untreated by the PWJ:

$$
R a_{\text {ratio }}=\frac{R a}{R a_{i n i}} .
$$

Table 2. Parameters of technological operations

\begin{tabular}{ll}
\hline Surface treatment & Technological parameters \\
\hline \multirow{2}{*}{ Rough milling } & Milling cutter Ø63 mm, 12 cutting edges, \\
& 360 RPM, traversing speed $65 \mathrm{~mm} \cdot \mathrm{min}^{-1}$ \\
\hline \multirow{2}{*}{ Fine milling } & $\begin{array}{l}\text { Milling cutter } \varnothing 63 \mathrm{~mm}, 12 \text { cutting edges, } \\
\text { 1500 RPM, traversing speed } 470 \mathrm{~mm} \cdot \mathrm{min}^{-1}\end{array}$ \\
\hline \multirow{2}{*}{ Planing } & $\begin{array}{l}\text { Planing machine } 52 \text { strokes per minute, } \\
\text { feed rate } 0.12 \mathrm{~mm} \text { per stroke }\end{array}$ \\
\hline Rolling & N/A \\
\hline
\end{tabular}

\section{EXPERIMENTS}

To enable to expose the sample surface to the effect of the pulsating water jet, the following testing procedure was developed (Fig. 2). A robotic arm ensured the nozzle movement with an exactly programmed trajectory. During experiments, the traversing speed of the nozzle was set to $(0.5,0.75,1.0,2.0$ and 4.0) $\mathrm{mm} \cdot \mathrm{s}^{-1}$; the stand-off distance was set to $55 \mathrm{~mm}$. This stand-off distance was determined as optimal for experimental conditions based on previous tests [8]. The angle of incidence was set to $90^{\circ}$.

The tests were performed at the operating pressure of $20 \mathrm{MPa}$ (the corresponding jet speed was approx. $180 \mathrm{~m} \cdot \mathrm{s}^{-1}$ ). Pressure pulsations were generated in a pulsating water jet generator at the frequency of $20.09 \mathrm{kHz}$ (the readout displayed by the ultrasonic generator); the amplitude of vibration of the ultrasonic sonotrode tip was set to $7 \mu \mathrm{m}$.

Each sample was exposed to the action of the pulsating jet in five areas according to a predefined 

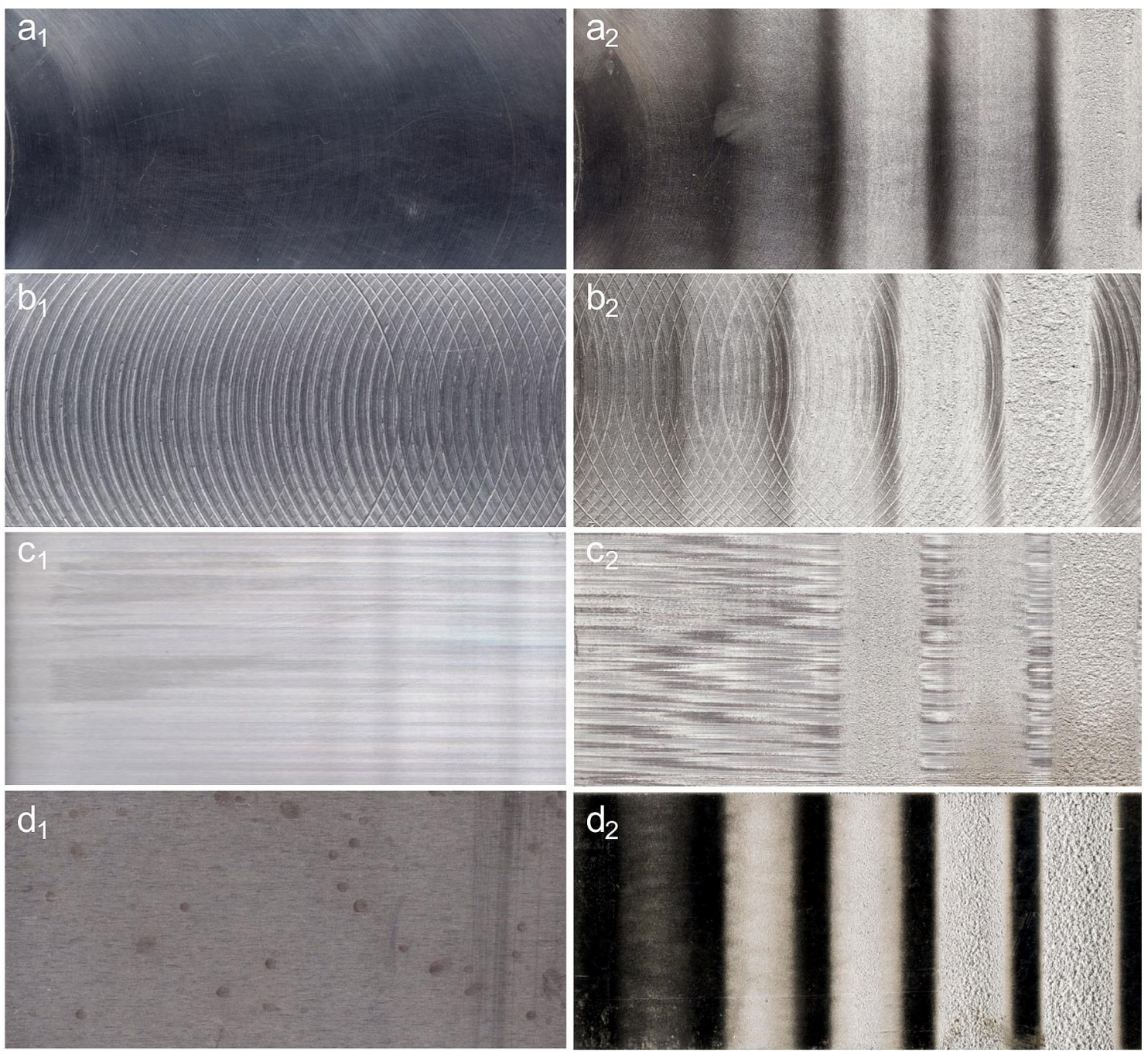

Fig. 1. Appearance of initial surfaces of EN AW $5083 \mathrm{H} 111$ samples after treatment by various technologies: a1) fine milling, b1) rough milling, c1) planing, d1) rolling; traces formed by PWJ on pre-treated surfaces: a2) fine milling, b2) rough milling, c2) planing, d2) rolling; traversing velocities on samples $a 2, b 2, c 2, d 2: 4.0,2.0,1.0,0.75$ and $0.5 \mathrm{~mm} \cdot \mathrm{s}^{-1}$ (from left to right)

experimental plan based on variations of the traversing speed of the pulsating water jet (Fig. 1).

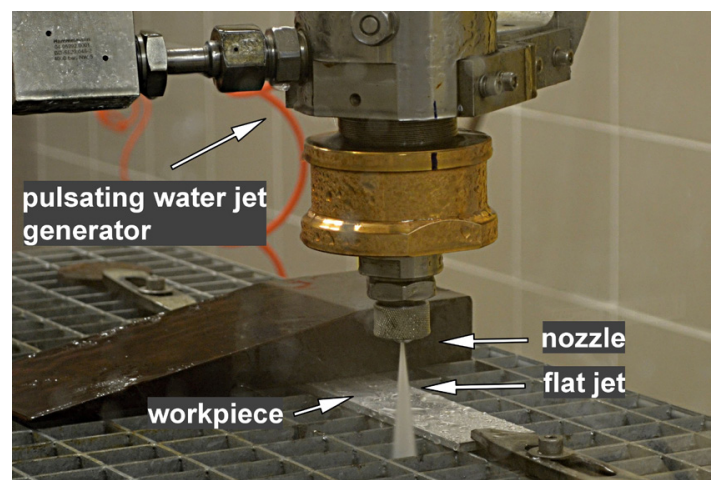

Fig. 2. Flat pulsating water jet used for surface treatment
Subsequently, the optical profilometer MicroProf FRT was used for the 3D determination of sample surfaces (Fig. 3).

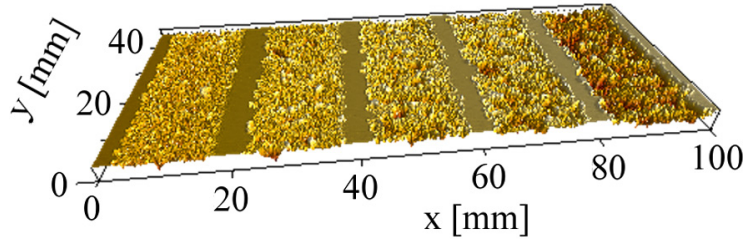

Fig. 3. 3D visualization of pre-treated (planed) surface

Measured data were processed using the SPIP software. Fig. 4 shows the areas of $40 \mathrm{~mm} \times 5 \mathrm{~mm}$ measured on tested surfaces. 


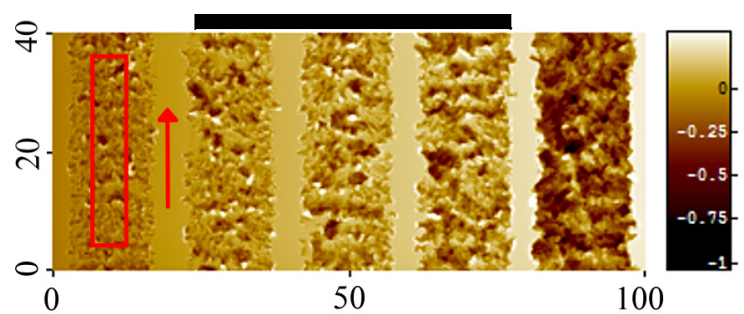

Fig. 4. Designation of measured areas and profile direction on pre-treated surface

The distance of measurement points for every tested surface profile was set to $4 \mu \mathrm{m}$ in $y$ direction and $250 \mu \mathrm{m}$ in $x$ direction. Then, five profiles in each kerf of the obtained topography were analysed. After averaging, the profile was analysed and the 2D surface parameter $R a$ was finally determined. It is the most commonly used parameter for assessing surface roughness. This parameter is included in the accuracy of the standards used in technical drawings and blueprints when not set a specific roughness of the surface. Statistically, this is a very stable and repeatable parameter.

\section{RESULTS}

The values of the parameter $R a$ in relation to the traversing speed of the jet $v$ and the initial surface treatment of a material are presented in Fig. 5.

The least roughened initial surface with an average value of $R a=0.5 \mu \mathrm{m}$ was achieved on a surface affected by the rolling technology. This value was measured in a direction perpendicular to the rolling direction. The roughness of $R a=0.9 \mu \mathrm{m}$ was achieved on a fine milled surface. The planing technology showed the roughness of $R a=2.6 \mu \mathrm{m}$ in a direction perpendicular to the direction of the cutter. The roughest surface with the value of $R a=4.5 \mu \mathrm{m}$ was created using the rough milling technology.

Obtained results indicate that the surface pretreatment of a material has a significant effect on the surface topography after the application of the pulsating water jet. Fig. 5 shows the surface roughness $R a$ in relation to the traversing speed $v$ on various tested surfaces. It can be observed that at the traversing speed $v=4.0 \mathrm{~mm} \cdot \mathrm{s}^{-1}$, the roughness $R a$ does not really differ from its initial values. The roughest surface is the rough milled surface, followed by the planed surface, then the rolled surface and finally the surface treated by the fine milling. At the traversing speed $v=2.0 \mathrm{~mm} \cdot \mathrm{s}^{-1}$, the PWJ has even stronger effect and roughness order of the rolled surface is changed. At the traversing speed $v=1.0 \mathrm{~mm} \cdot \mathrm{s}^{-1}$, the PWJ effect on material surface is very strong and the roughness of the rolled surface increases rapidly. In contrast, the parameter $R a$ does not change considerably on both roughly and finely milled surfaces. At the traversing speed $v=0.75 \mathrm{~mm} \cdot \mathrm{s}^{-1}$, the value of $R a$ for fine milled surface is still low. The $R a$ value increases significantly in case of other surfaces. At the lowest traversing speed $v=0.5 \mathrm{~mm} \cdot \mathrm{s}^{-1}$, very large volume removal occurs on every surface. Accordingly, the value $R a$ increases significantly on all surfaces.

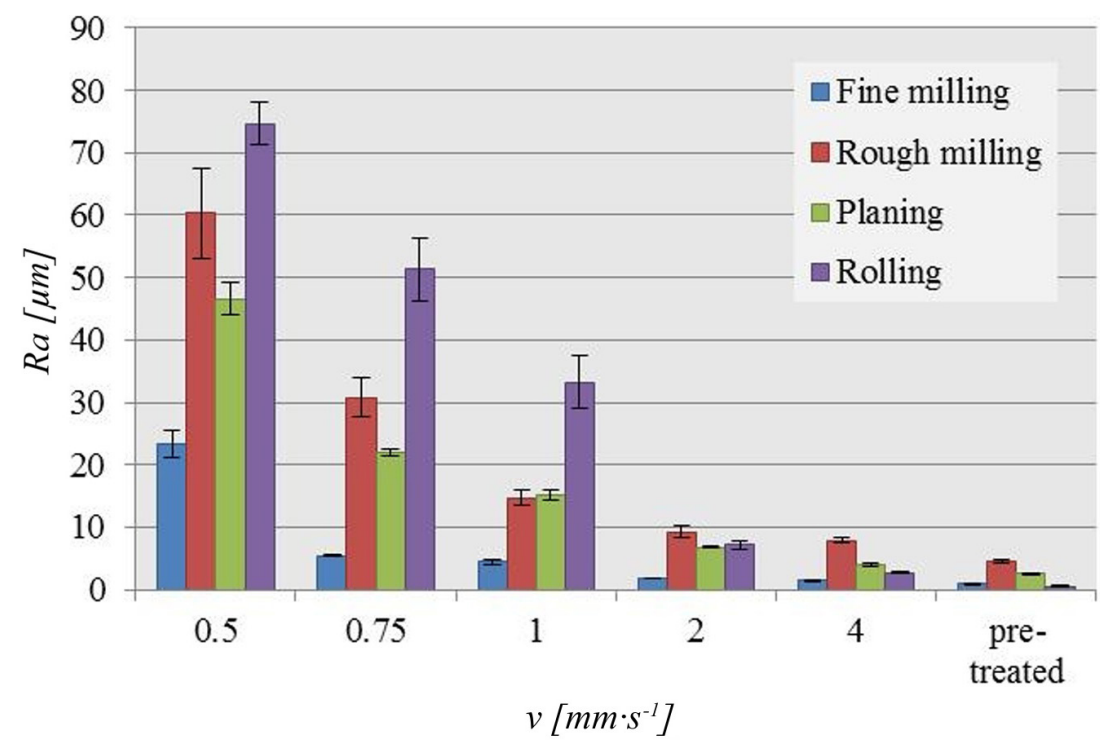

Fig. 5. Effect of traversing speed $v$ on arithmetical mean of profile Ra 


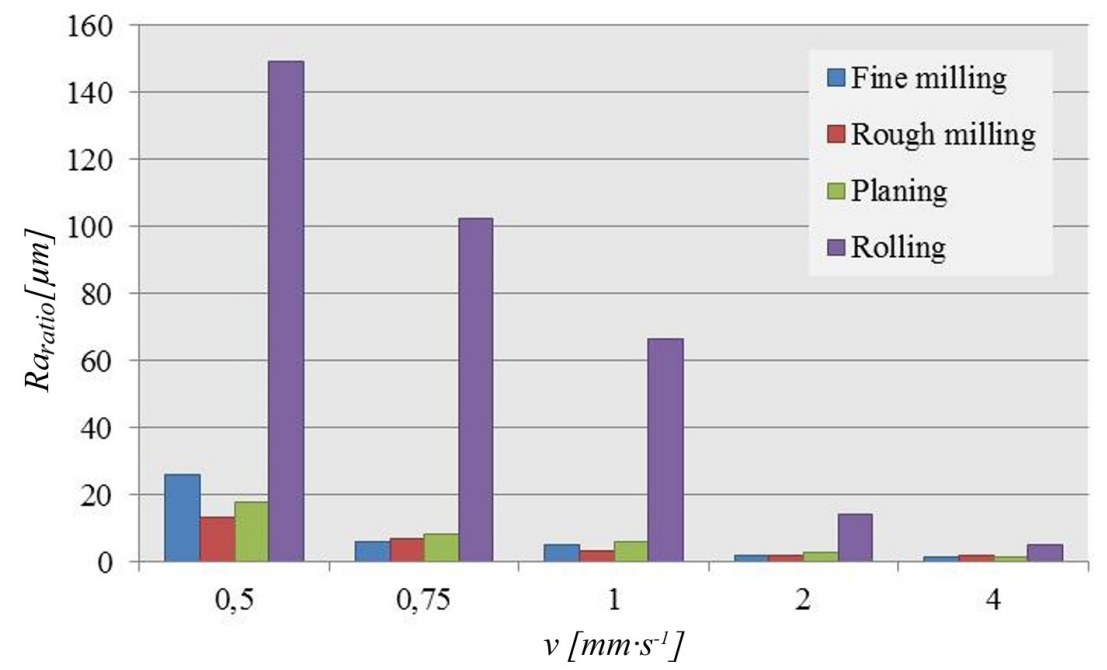

Fig. 6. Relative roughness Raratio between original surfaces and the surfaces affected by PWJ at different traversing speed $v$

If we look at Fig. 6 showing the ratio of the roughness $R a$ before and after the PWJ action, we can realize that the roughness of the rolled surface treated by the PWJ at the traversing speed $v=0.5 \mathrm{~mm} \cdot \mathrm{s}^{-1}$ has increased 150 times, by other surfaces only approximately 20 times.

\section{DISCUSSION}

The assumptions that surfaces with significant roughness (after rough milling) disrupt the effect of the PWJ and that the radial flow of the liquid along the surface aligns peaks created by rough milling were confirmed. Values of roughness $R a$ are very similar to the values of the rolled and milled surfaces before the PWJ action. However, significant difference between these two surfaces occurs after using the PWJ. This could be caused by hardening of the surface layer during milling, which results in its greater resistance to the impact of the PWJ.

Surfaces treated by pulsating jets show larger effective area compared to those treated by continuous jet [17]. This knowledge could be utilized in applications where good adhesion of coating layer or new overlay material to substrate surface both in tension and shear is needed.

This feature of pulsating jets was confirmed by tests on repair of concrete structures. Generally speaking, repair materials better adhere to rough surface. Toutanji and Ortiz [18] reported that surface treatment by water jet produces a better bonding strength than surface treatment by sander. It was found [19] that the pulsating jet produces more "rough" surface with larger effective surface area compared to continuous one. During standard pull-off tests average bonding strength in the cases of the pulling off carried out on the contact between mortar and concrete was by about $38 \%$ higher in the case of surfaces treated with pulsating water jet than in the cases of surfaces treated with continuous water jet [20].

\section{CONCLUSIONS}

Experimental work oriented on the evaluation of effects of the pulsating water jet on surfaces treated by different technologies shows that the erosion caused by repeated impacts of water pulses depends on the initial conditions of a material surface.

Generally, the highest values of roughness after the pulsating water jet application were achieved on surfaces pre-treated by the rolling and consequent annealing which relieved stresses in surface layer. In contrast, other surface treatments based on various machining methods strengthened surface layers and thereby hindered the jet from easy penetration into the material.

Practical meaning of this experiment is to determine which kind of surface is optimal for subsequent using of pulsating water jet. This could help to optimize the process and reduce costs in production. During the subsequent treatment of the surface, the parameters are intended by the pretreatment technology. For example, travel speed or water pressure, which affects the economy significantly. 
Next steps of the research in this area will be oriented at the study of the influence of the surface layer hardness on the erosion process caused by effects of the pulsating water jet and the investigation of changes of properties of surface layers due to impacts of the water pulses.

\section{ACKNOWLEDGEMENTS}

Presented work has been supported by the ASCR project No. AV0Z30860518 and by the Ministry of Industry and Trade of the Czech Republic project No. FV 10446 and the project Institute of Clean Technologies for Mining and the Utilization of Raw Materials for Energy Use - Sustainability program, reg. no. LO1406 financed by the Ministry of Education, Youth and Sports of the Czech Republic.

\section{REFERENCES}

[1] Cook, S.S. (1928). Erosion by water-hammer. Proceedings of the Royal Society A Mathematical, Physical and Engineering Science, vol. 119, no. 783, p. 481-488, D0l:10.1098/ rspa.1928.0107.

[2] Foldyna, J., Sitek, L., Ščučka, J., Martinec, P., Valí̌ek, J., Páleníková., K. (2009) Effects of pulsating water jet impact on aluminium surface. Journal of Materials Processing Technology, vol. 209, no. 20, p. 6174-6180, D0l:10.1016/j. jmatprotec.2009.06.004.

[3] Bai, C., Chandra, S., Daniels, B., Ren, B., Yan, W., Tieu, A., Vijay, M. (2006). Abrasive-Entrained High-Frequency Pulsed Waterjet: Basic Study and Applications. Proceedings of the $18^{\text {th }}$ International Conference on Water Jetting, p. 325-336.

[4] Bach, F.W., Schenk, A., Kremer, G., Biskup, C., Meier, O., Fargas, M., Bunte, J., Jäschke, P. (2006). Increase of erosive potential of water jets by laser pulsing. Proceedings of the $18^{\text {th }}$ International Conference on Water Jetting, p. 357-366.

[5] Foldyna, J., Švehla, B., (2008). Method of Generation of Pressure Pulses and Apparatus for Making the Same. CZ patent 299412, Industrial Property Office, Praque.

[6] Sitek, L., Foldyna, J., Martinec, P., Ščučka, J., Bodnárová, L., Hela, R. (2011). Use of pulsating water jet technology for removal of concrete in repair of concrete structures. Baltic Journal of Road and Bridge Engineering, vol. 6, no. 4, p. 235242, D0I:10.3846/bjrbe.2011.30.

[7] Riha, Z., Foldyna, J. (2012). Ultrasonic pulsations of pressure in water jet cutting tool. Tehnicki Vjesnik - Technical Gazette, vol. 19, no. 3, p. 487-491.

[8] Foldyna, J., Klich, J., Hlaváček, P., Zeleňák, M., Ščučka, J. (2012). Erosion of metals by pulsating water jet. Tehnicki Vjesnik - Technical Gazette, vol. 19, no. 2, p. 381-386.

[9] Asad, M., Mabrouki, T., Girandin, F., Yhang, Z., Rigal, J.F. (2011). Towards a physical comprehension of material strengthening factors during macro to micro-scale milling. Mechanics, vol. 17, no. 1, p. 97-104, D0l:10.5755/j01. mech.17.1.210.

[10] Rao, S., Shunmugam, M.S. (2012). Analytical modelling of micro end-milling forces with edge radius and material strengthening effects. Machining Science and Technology, vol. 16, no. 2, p. 205-227, Dol:10.1080/10910344.2012.673966.

[11] Lehocka, D., Klich, J., Foldyna, J., Hloch, S., Krolczyk, J.B., Carach, J., Krolczyk, G.M. (2016). Copper alloys disintegration using pulsating water jet. Measurement, vol. 82, p. 375-383, D0l:10.1016/j.measurement.2016.01.014.

[12] Hreha, P., Hloch, S., Monka, P., Monková, K., Knapčíková, L., Hlaváček, P., Zeleňák, M., Samardžić, I., Kozak, D. (2014). Investigation of sandwich material surface created by abrasive water jet (AWJ) via vibration emission. Metalurgija, vol. 53, no. 1, p. 29-32.

[13] Hreha, P., Radvanská, A., Cárach, J., Lehocká, D., Monková, K., Krolczyk, G., Ruggiero, A., Samardzić, I., Kozak, D., Hloch, S. (2014). Monitoring of focusing tube wear during abrasive waterjet (AWJ) cutting of AISI 309. Metalurgija, vol. 53, no. 4, p. 533-536.

[14] Hreha, P., Radvanská, A., Hloch, S., Peržel, V., Królczyk, G., Monkova, K. (2014). Determination of vibration frequency depending on abrasive mass flow rate during abrasive water jet cutting. The International Journal of Advanced Manufacturing Technology, vol. 77, no. 1, p. 763-774, Dol:10.1007/s00170014-6497-9.

[15] Krolczyk, G., Legutko, S. (2014). Experimental analysis by measurement of surface roughness variations in turning process of duplex stainless steel. Metrology and Measurement Systems, vol. 21, no. 4, p. 759-770, Dol:10.2478/mms-20140060.

[16] Wojciechowski, S., Twardowski, P., Wieczorowski, M. (2014). Surface texture analysis after ball end milling with various surface inclination of hardened steel. Metrology and Measurement Systems, vol. 21, no.1, p. 145-156. DOl:10.2478/mms-2014-0014.

[17] Sitek, L., Foldyna, J., Martinec, P., Ščučka, J., Bodnárová, L., Hela, R. (2011). Use of pulsating water jet technology for removal of concrete in repair of concrete structures. The Baltic Journal of Road and Bridge Engineering, vol. 6, no. 4, p. 235242, D0I:10.3846/bjrbe.2011.30.

[18] Toutanji, H., Ortiz, G. (2001). The effects of surface preparation on the bond interface between FRP sheets and concrete members. Composite Structures, vol. 53, no. 4, p. 457-462, DOl:10.1016/S0263-8223(01)00057-5.

[19] Sitek, L., Foldyna, J., Ščučka, J., Mlynarczuk, M., Sobczyk, J. (2002). Quality of bottom surface of kerfs produced by modulated jets. Proceedings of the $16^{\text {th }}$ International Conference on Water Jetting, p. 359-368.

[20] Sitek, L., Foldyna, J., Klich, J., Bodnárová, L., Wolf, I. (2012). Aplications of oscilating waterjets to in situ removing of decomposed surface layers of concrete. Tunel, vol. 21, no. 2, p. 16-26. 